\title{
Psychological morbidity and autonomic reactivity to emotional stimulus in parental cancer: a study with adult children caregivers
}

\author{
R.J. TEIXEIRA, PHD, University of Minho, School of Psychology, Braga, \& M.G. PEREIRA, PHD, University of Minho,
} School of Psychology, Braga, Portugal

TEIXEIRA R.J. \& PEREIRA M.G. (2014) European Journal of Cancer Care 23, 129-139

Psychological morbidity and autonomic reactivity to emotional stimulus in parental cancer: a study with adult children caregivers

Literature suggests that parental cancer can provoke aversive emotional arousal in adult children, who may perceive caregiving as a traumatic experience. Limited research has been conducted on emotional and physiological impact of family caregiving for cancer patients undergoing chemotherapy. The aim of the present study was to examine psychological and physiological responses in parental cancer's caregivers. Two matched groups of adult children, with 78 participants each (parental cancer vs. control), completed psychological measures of distress, post-traumatic stress disorder (PTSD) symptoms, and burden. Additionally, each participant visualised standardised pictures with different emotional valences, while cardiovascular (heart rate) and electrodermal responses (skin conductance) were recorded. Between-group analysis showed significant differences on all psychological variables, and on skin conductance for all types of pictures. However, for the heart rate responses, differences were found only for pictures with unpleasant emotional arousal. In the parental cancer group, the heart rate peak response stood out as a predictor of PTSD symptoms, after controlling for distress and burden. This study highlights the important role of psychophysiological measures of family caregiving in oncology. Physiological responses may explain a higher prevalence of PTSD symptoms. Therefore, biofeedback combined with targeted psychosocial interventions for relaxation could be of great clinical value for this population.

Keywords: parental cancer, caregiving, adult children, emotional, psychophysiological research.

\section{INTRODUCTION}

Caring for a family member is a psychologically demanding experience, associated with more non-psychiatric hospitalisations (Chentsova-Dutton et al. 2000), chronic diseases, medication use (Schulz et al. 1995), and even mortality (Schulz \& Beach 1999), than non-caregivers. In addition to concerns regarding the family member's welfare, caregivers of cancer patients report high levels of psychological distress. However, it remains unclear

Corresponding address: Ricardo J. Teixeira, University of Minho, School of Psychology. Campus de Gualtar, 4710-057 Braga, Portugal (e-mail: ricardojf@@gmail.com).

Accepted 22 June 2013

DOI: $10.1111 /$ ecc. 12102

European Journal of Cancer Care, 2014, 23, 129-139 whether this distress also has an effect on the physical body. Research has reported a broad array of humoral, immune, cardiovascular and metabolic alterations in caregivers of patients with dementia (Vedhara et al. 1999; Vitaliano et al. 2002, 2003; Kiecolt-Glaser et al. 2003; Gallagher-Thompson et al. 2006; von Känel et al. 2006); however, it has not explored in depth, whether caregiving demands a similar toll on the bodies of those caring for a family member with cancer. In comparison with other caring contexts, caregivers in oncology present distinct characteristics: they are usually younger and provide assistance for shorter periods of time for patients that often have specific symptoms (e.g. pain, vomiting) (Chentsova-Dutton et al. 2002; Hauser \& Kramer 2004). Some preliminary reports suggest the possibility that cancer caregiving may increase vulnerability to coronary 
disease, as well as other metabolic, autoimmune, inflammatory, and psychiatric conditions (Vanderwerker et al. 2005; Rohleder et al. 2009).

Physiological measures may help to explain the associations between caregiving and illness, much earlier than the manifestation of chronic diseases (Vitaliano et al. 2003). In oncology, few investigations have been performed on the interaction between the bio-behavioural responses to stress in household care providers. For Sherwood et al. (2008), physiological responses are considered 'adaptive' in the initial reaction to acute stress (e.g. a diagnosis of primary malignant brain tumour and initial treatment); however, for continuous stress or chronic situations (e.g. disease progression or long-term treatment), physical responses may lead to changes in the cardiovascular and immune systems (via cortisol), which will compromise the state of general physical health of the caregiver. In this context, recent studies have shown that caregivers of cancer patients manifest increased cardiac activity (sympathetically controlled) as well as an increase in systolic and diastolic blood pressure (Weitzner et al. 2000; Lucini et al. 2008; Corà et al. 2012), two cardiovascular measures commonly used in Psychophysiology (Orr \& Roth 2000). Cardiovascular activity varies depending on psychological aspects (emotional changes) and is, therefore, important as an autonomic physiological variable (Arangüena \& Dorado 2000). Many epidemiological studies on the impact of elevated heart rate (HR) on health, report an increased risk of all-cause mortality and cardiovascular events (Dimsdale 2008), particularly in hypertensive caregivers (Vitaliano et al. 1993; Shaw et al. 2003).

Another common physiological variable is electrodermal activity, an important indicator of the sympathetic nervous system's activation, especially useful to assess emotional reactivity (Orr \& Kaloupek 1997; Sequeira et al. 2009). No studies were found with caregivers of cancer patients that included electrodermal activity as a measure. In general, research on the use of this physiological variable in studies with caregivers is very scarce, presenting results that are either inconclusive (Stampler et al. 1997; Thompson et al. 2004; Lewis et al. 2008) or contradictory (Moya-Albiol et al. 2011).

Research shows that adult children of parents with chronic illness have an increased risk of developing emotional and behavioural problems than adult children of healthy parents. The risk, however, depends on individual and family variables related to the disease itself (Korneluk \& Lee 1998). Cancer is currently conceptualised as a possible precipitator of post-traumatic stress disorder (PTSD) symptoms (American Psychiatric Association 2000), both in patients and in first-degree relatives.
Research suggests that first-degree relatives of patients with cancer have significantly higher levels of intrusive cancer-related thoughts and avoidance, compared with relatives without a family history of cancer (Zakowski et al. 1997; Baider et al. 1999), 4\% showed symptoms consistent with a PTSD diagnosis, $7 \%$ showed symptoms consistent with subclinical levels of potential PTSD (probably cancer-related) (Lindberg \& Wellisch 2004), and 53\% had considerable intrusive thoughts, comparable to those found in studies of individuals exposed to other types of trauma (Lerman et al. 1993). However, the unique aspects of the cancer experience associated with other types of trauma, and the overlap between normative reactions to cancer and the PTSD response, confounds the interpretation of these results.

Given the great variability in distress levels among first-degree relatives of patients with cancer (Lerman et al. 1993; Erblich et al. 2000), it is important to assess the main predictors of their responses to stress. Considering the limited research with physiological variables among cancer caregiver's samples, an experimental design was used in order to assess and compare adult children caregivers of cancer patients with a control group. Research widely supports the importance of considering physiological variables in the study of PTSD (Pole 2007). For example, enhanced physiological reactivity to trauma cues has been shown to be a robust correlate of PTSD (Elsesser et al. 2009). Considering the most commonly used experimental designs in this field (Orr \& Roth 2000; Bryant et al. 2003; Elsesser et al. 2004, 2005, 2009; O'Donnell et al. 2007; Ehlers et al. 2010; Suendermann et al. 2010), the paradigm of affective picture viewing (with different valences) (Lang et al. 1993) was the selected method to evoke and register physiological responses.

In the present study, adult children caregivers with parental cancer and controls were compared for psychological morbidity, evoked $\mathrm{HR}$, and skin conductance responses (SCR) to idiosyncratically caregiving-related (unpleasant) and control pictures (pleasant and neutral). In keeping with some previous reports, the parental cancer group was expected to exhibit a higher level of psychological morbidity and enhanced psychophysiological reactivity than controls. Finally, distress, burden and physiological reactivity were expected to be predictive of PTSD symptoms in parental cancer participants.

\section{METHODS}

\section{Procedures and participants}

A cross-sectional experimental study with two convenience samples was used. The research design was approved 
by the Ethic Committee of a general hospital in northern Portugal. Participation was voluntary. The parental cancer group $(n=78)$ consisted of adult children who, during the period of data collection, accompanied the parent diagnosed with cancer to chemotherapy. Among these eligible caregivers, only one refused to participate in the study. Seventy-seven per cent were women, with a mean age of 34.4 years $(\mathrm{SD}=9.2) ; 53 \%$ had a partner; $76 \%$ had graduated from high school. Parents' tumour sites were heterogeneous. Inclusion criteria required participants to be $\geq 18$ years old; have a parent (or both) in chemotherapy; accompany the parent to the hospital for treatment; and not suffer from oncological, psychiatric, or neurological disease. Sixty per cent reported to provide care for less than one year, and only $39 \%$ provided care for more than a year. Only $19 \%$ of adult children perceived the parent in treatment as completely dependent on their caregiving. The control group $(n=78)$ consisted of adult children without a chronically ill parent, recruited at a university. Seventy-six per cent were women, with a mean age of 32.2 years $(S D=9.8) ; 56 \%$ had a partner; $86 \%$ had graduated from high school. Comparatively, groups showed no significant differences in terms of gender $\left[\chi^{2}(1, N=156)=\right.$ $0.035, P=$ n.s. $]$, age $[t(160)=-1.459, P=$ n.s. $]$, marital status $\left[\chi^{2}(1, \mathrm{~N}=156)=0.233, P=\right.$ n.s. $]$, and education level $\left[\chi^{2}(1, \mathrm{~N}=156)=2.641, P=\right.$ n.s. $]$.

Each participant completed self-report measures, and was subjected to an experimental task that consisted of a psychophysiological test in which autonomic responses were evoked through the presentation of pictures with different emotional valences. Participants were informed that the purpose of the task was to measure bodily responses to pictures. They were instructed to sit down in a comfortable position and try to move as little as possible during the task. They were asked to look at each picture carefully. An effort was made to control environmental conditions, such as temperature and noise. Data of three participants were discarded from statistical analysis due to the presence of artefacts in their recordings.

\section{Materials}

\section{Depression anxiety stress scales}

The Portuguese version of the 21-item Depression Anxiety Stress Scales (DASS-21; Lovibond \& Lovibond 1995; Pais-Ribeiro et al. 2004) was used. It comprises a 4-point set (0-3) of three subscales (depression, anxiety, and stress). In this study, only the total score was used. Higher scores in the DASS-21 indicate greater 'distress'. The internal consistency in the parental cancer group and in the control group was 0.96 and 0.87 respectively.

\section{Burden assessment scale}

The Portuguese version of the Burden Assessment Scale (BAS; Reinhard et al. 1994) was used. This is a 19-item measure that evaluates burden in an objective way, i.e. the amendment of caring for someone with limitations imposed on activities and resources of the caregiver. BAS uses a 4-point scale (1-4), with higher scores indicating greater levels of caregiving burden. Control participants were asked to focus on any experience of their personal life in which they had provided some type of care to a loved one. The internal consistency in the parental cancer group and in the control group was 0.84 and 0.89 respectively.

\section{Impact of event scale - revised}

To assess PTSD-related symptoms, the Portuguese version of the Impact of Event Scale - Revised (IES-R; Weiss \& Marmar 1997) was used. This is a 22-item selfreport measure of current subjective distress related to a specific traumatic event. Respondents are asked to rate on a 5-point scale (0-4) how distressing symptoms of avoidance, hyperarousal, and intrusion have been in the past 7 days. In this study, only the total score was used. Control participants were asked to rate items with regard to their most stressful life-event. Research supports the score of 33 on the IES-R as representing the best cut-off for a probable diagnosis of PTSD (Creamer et al. 2003; Wang et al. 2011). Whereas the scores of the subscales and total IES-R are expressed as means (Weiss \& Marmar 1997), for cutoff analysis purposes the sum of the results in the 22 items, was used. The internal consistency in the parental cancer group and in the control group was 0.93 and 0.94 respectively.

\section{Visual stimuli}

Pictures were drawn from the International Affective Picture System (IAPS; Lang et al. 2008). Participants viewed 15 idiosyncratic pictures related to the oncology caregiving condition and considered as 'unpleasant ${ }^{11}$ (e.g. mastectomy, ventilator), 15 'neutral' pictures (e.g. table, lamp, mug), and 15 'pleasant' pictures (e.g. sunset, baby, tiger). The pictures were presented in a predefined order so that the same category was not presented twice in a row, to minimise habituation effects. After a $120 \mathrm{~s}$ baseline,

${ }^{1}$ IAPS No (unpleasant): 9432, 2141, 2205, 3220, 7521, 2490, 9596, 2590, $3261,2900,7520,2700,2800,3230,6000$; (neutral): 7010, 6150, 7002, 7009, 7020, 7000, 7040, 7004, 7012, 7175, 7150, 7025, 7185, 7170, 7006; (pleasant): 1460, 1440, 2550, 1811, 2530, 2540, 2057, 2165, 2170, 2340, 8497, $2360,2341,1463,5829$. 
each picture was presented for $6 \mathrm{~s}$ followed by an interstimulus interval of $12 \mathrm{~s}$. Pictures were selected from a larger set in a pilot study that tested the suitability of the stimulus material with 16 healthy volunteers. Pleasant and unpleasant pictures had similar arousal levels, whereas the neutral ones presented a lower arousal level (Lang et al. 2008). The classification of IAPS stimuli by 'pilots' was performed with a simple table in which each picture was evaluated for valence: unpleasant, pleasant, or neutral.

\section{Apparatus and physiological recording}

The I-330-C2 recording device and USE3 Physiolab software (both by J\&J Engineering) were used, a system that digitally records physiological data online at a sample rate of 1.024 samples/s across all channels. Raw ECG data were collected with gel-free sensor MC-5D, a reusable HR sensor placed in a standard bilateral configuration on the palmar side of each wrist. The data were processed through a $1-400 \mathrm{~Hz}$ bandpass filter designed to maximise R-wave frequency. Skin conductance (SC) levels were obtained using a skin resistance sensor cable MC-6SY (range 0-20 microsiemens; $\mu \mathrm{S}$ ) connected to SE-35 electrodes $(\mathrm{Ag}-\mathrm{AgCl})$ placed on the middle phalanx of the second and third fingers of the non-dominant hand. During the presentation of pictures, the participant's HR and SC were recorded continuously.

\section{Data reduction}

\section{$H R$ responses}

R-R intervals (time between heartbeats) were converted online into HR (in beats per minute; 'bpm'), and outputted to obtain one weighted HR estimate for each second. HR recordings were inspected for artefact control. By picture set (unpleasant, neutral, and pleasant), the following data were obtained: pre-stimulus HR baseline, HR response for each second of picture presentation, and peak HR response. For each picture, the pre-stimulus baseline HR was defined as the HR during the last second prior to picture onset (Hamm et al. 1997; Bradley et al. 2001; Elsesser et al. 2004). HR response was assessed as the relative change from baseline during the $6 \mathrm{~s}$ of stimulus presentation (Ehlers et al. 2010), i.e. for each second of stimulus presentation, the pre-stimulus baseline HR was subtracted from the HR during that second. Finally, the maximum of the HR responses for each second of stimulus presentation was used to index peak HR response. Some literature claims the use of an additional cardiac indicator, namely the relative acceleration in HR (Blanchard et al. 1996; Elsesser et al. 2005; Ehlers et al. 2010). Therefore, considering that this acceleration is more prevalent during the presentation of aversive stimuli, this record was only calculated for the selected unpleasant pictures, i.e. in case of a mean acceleration over $1 \mathrm{bpm}$, relative to pre-stimulus baseline.

\section{SC responses}

Skin conductance data were outputted in quarters of a second $(0.25 \mathrm{~s})$, in order to produce a more accurate latency. Artefact-free SCR were scored as the largest change (peak-valley difference) above $0.01 \mu \mathrm{S}$ occurring in a 1-4 s time window following picture onset (Levinson \& Edelberg 1985; Dawson et al. 2007). All responses lower than $0.01 \mu \mathrm{S}$ were computed as zero (SCR magnitude was the preferred outcome). To avoid positive asymmetry and leptokurtic distribution issues, a logarithmic transformation [ $\log (\mathrm{SCR}+1)]$ was conducted to normalise the data (Venables \& Christie 1980; Dawson et al. 2007). For each picture set (unpleasant, neutral, and pleasant), an average record of the normalised SCR magnitude was obtained.

\section{Statistical analyses}

Socio-demographic group differences were analysed using $t$-tests and chi-squared. For differences between groups considering psychological variables, ANOva was used. Differences in PTSD severity (categorical variable) were analysed using chi-squared. Although the 'classical' method for data analysis in Psychophysiology is the analysis of variance (ANOva with Repeated Measures), in this study for group comparisons of physiological data, the multivariate approach (MANOvA) was preferred (Jennings \& Gianaros 2007) as it has the advantage, compared with the classical ANOVA-RM, of not requiring the assumption of sphericity, which causes some authors to advocate its use (Field 2006; Tabachnick \& Fidell 2006). Hierarchical multiple regression analysis was conducted in order to examine the main psychological and physiological predictors of PTSD symptoms. Finally, a hierarchical logistic regression analysis was performed with the same previous predictors, in order to examine the main contributors to a probable diagnosis of PTSD based on a cut-off point in the IES-R. This methodological option was preferred to discriminant analysis, due to the fact that one of the independent variables included in the model was dichotomous (HR acceleration $>1 \mathrm{bpm}$ ). 


\section{RESULTS}

\section{Group differences}

Participants with and without parental cancer did not differ in gender, age, marital status, or education. As expected, the parental cancer group reported more distress, burden, and PTSD symptoms, compared with the group without parental cancer (see Table 1). These differences were also significant for PTSD severity. As shown in Table 1, the selected cut-off in the IES-R permitted the determination of the prevalence of PTSD possible cases in the parental cancer group ( $n=36$ patients, $46.2 \%)$ and in the control group $(n=10$ cases, $12.8 \%)$, with a sensitivity of $46 \%$ and a specificity of $87 \%\left[\chi^{2}(1, \mathrm{~N}=156)=20.841\right.$, $P<0.001, \Phi=0.366, \mathrm{OR}=6.14]$.

Baseline HR (120 s) differ between participants with parental cancer $(\mathrm{M}=79.90, \mathrm{SD}=11.86)$ and those without chronically ill parents $(\mathrm{M}=75.11, \mathrm{SD}=10.53), P<0.01$. The same was found in SC baseline (120 s), since participants with parental cancer $(\mathrm{M}=10.45, \mathrm{SD}=7.28)$ showed higher electrodermal reactivity at baseline compared with participants without a chronically ill parent $(M=6.22$, $\mathrm{SD}=3.63), P<0.001$.
After obtaining baseline HR data, significant differences between groups were found in all picture valences (unpleasant, neutral, and pleasant) but solely on prestimulus baseline HR (see Table 1). However, for unpleasant pictures, other cardiac indicators differ between groups, namely the mean HR of the $6 \mathrm{~s}$, and the HR acceleration above $1 \mathrm{bpm}$. Considering that the mean HR is the relative difference from pre-stimulus baseline, the parental cancer group showed greater HR responses, combined with a less pronounced deceleration, to unpleasant pictures compared with controls $(P<0.01)$. Regarding data of the HR acceleration exceeding $1 \mathrm{bpm}$ for unpleasant stimuli, they allowed the disclosure of differences between groups, with the parental cancer group $\mid n=15$ cases, $19.2 \%$ ) showing a greater acceleration, compared with controls $(n=6$ cases, $7.7 \%)\left[\chi^{2}(1, \mathrm{~N}=156)=4.457\right.$, $P<0.05, \Phi=0.169$, OR $=2.89]$. The mean peak HR responses did not differ in any picture valence. However, for unpleasant pictures there was a trend $(P=$ 0.085 ) for higher scores in the parental cancer group (Table 1).

For each second of picture presentation, differences between groups were found for unpleasant pictures, while

Table 1. Differences between groups ( $n$ and percentages, or mean and standard deviation)

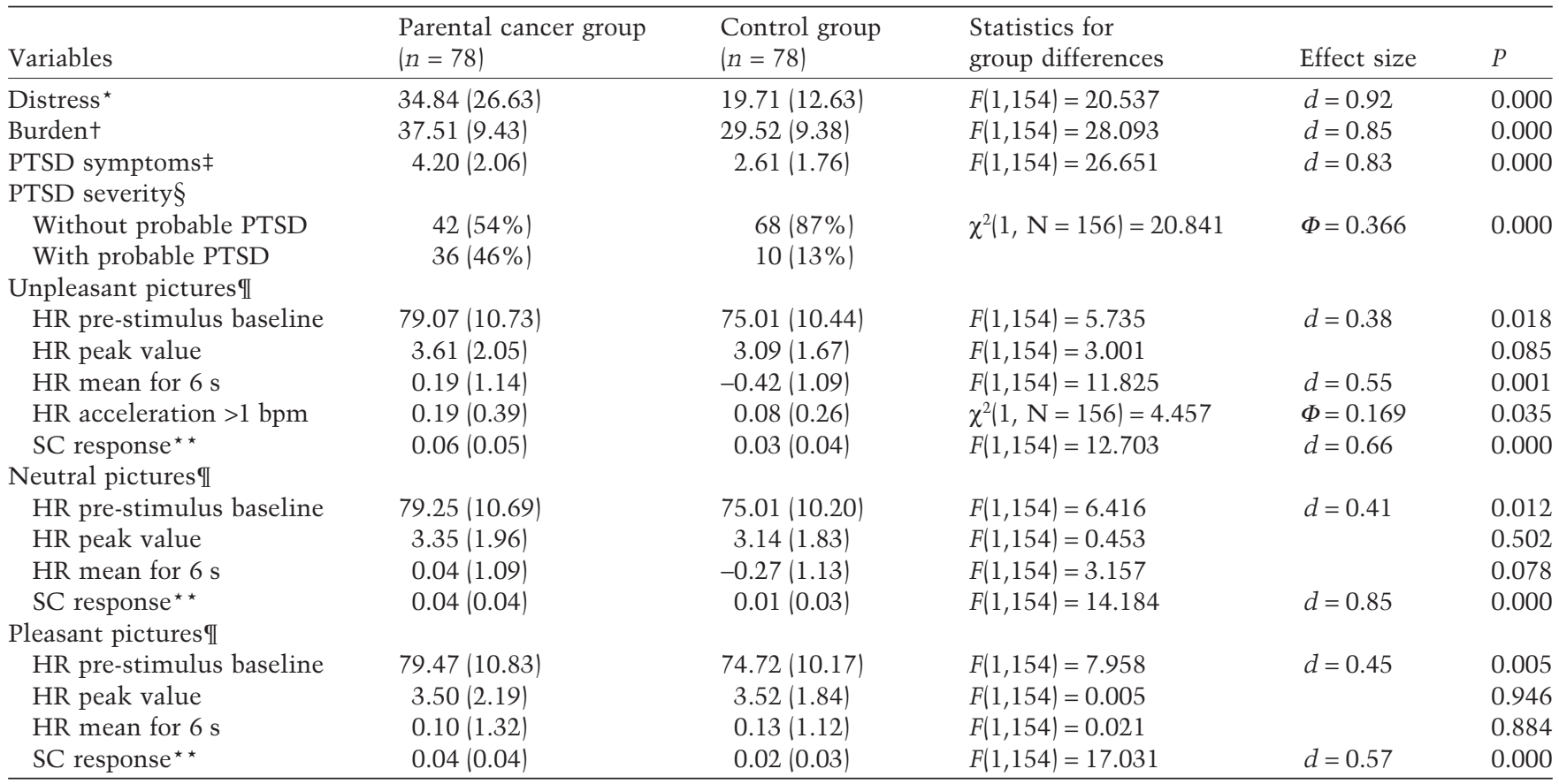

Note. For each significant comparison, Cohen's $d$ and Cramér's $\Phi$ were calculated as indexes of effect size.

${ }^{\star}$ Depression Anxiety Stress Scales.

tBurden Assessment Scale.

$\ddagger$ Impact of Event Scale-Revised.

$\S U$ sing the cut-off of 33 in the IES-R.

IIIAPS pictures emotional valence.

${ }^{\star \star} \log (\mathrm{SCR}+1)$.

PTSD, post-traumatic stress disorder; HR, heart rate; SC, skin conductance. 
this was not the case for neutral or pleasant ones. These differences were significant at all seconds, except for the fourth second (only a trend was found, $P=0.067$ ). Figure 1 shows the mean HR responses to the unpleasant pictures during the $6 \mathrm{~s}$ of stimulus presentation for both groups.

Concerning SCR's magnitude, data showed differences between groups in all picture valences (see Table 1).

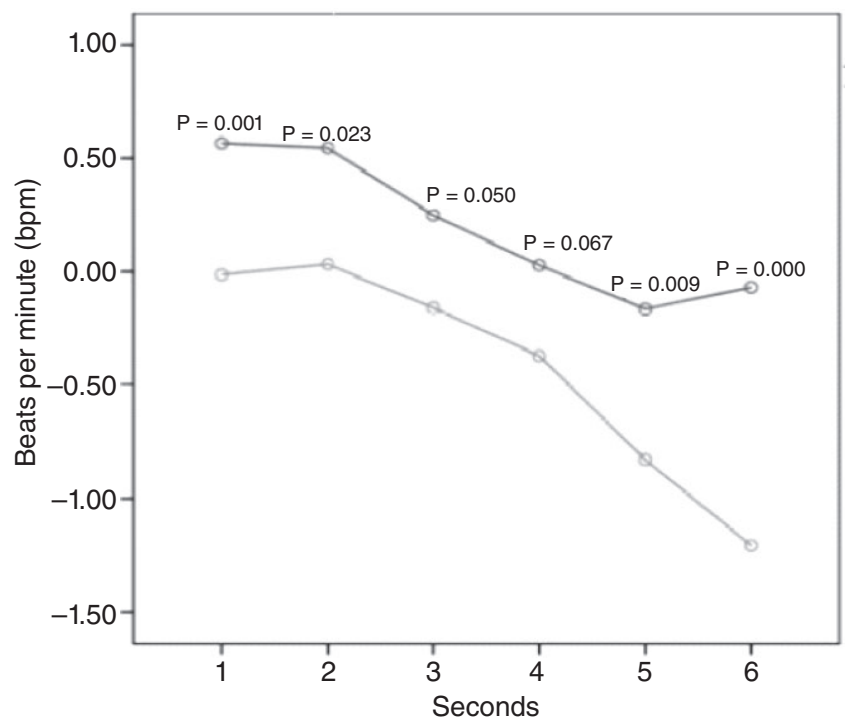

Figure 1. Mean HR responses to unpleasant pictures for the two groups during the $6 \mathrm{~s}$ of stimulus presentation, relative do prestimulus baseline. — , parental cancer group; $\_$, control group.

\section{Predictors of PTSD symptoms and severity in the parental cancer group}

A hierarchical multiple regression analysis was used to test how accurately PTSD symptoms can be predicted based on psychological variables (previously identified) and HR responses, considering prior reports (Blanchard et al. 1996; Elsesser et al. 2005; Ehlers et al. 2010). Distress and caregiver burden were entered in Step 1; peak HR responses (to unpleasant, neutral, and pleasant pictures) and the HR acceleration exceeding $1 \mathrm{bpm}$ were entered in Step 2. The regression model explained $48 \%$ of the observed variance $[F(6,71)=10.922, P<0.001]$. Table 2 shows distress and burden to be significant predictors of higher correlates of PTSD symptoms. Furthermore, peak HR responses, to unpleasant pictures, significantly increased the accuracy of prediction. Peak responses to pleasant and neutral pictures did not contribute to the model, as well as HR acceleration $>1 \mathrm{bpm}$ to unpleasant pictures.

Statistical procedures were also performed to find whether the same psychological and physiological variables allowed a distinction of parental cancer participants based on a cut-off for a probable PTSD diagnosis. In this content, a hierarchical logistic regression analysis was conducted. Distress and burden were entered in Step 1, significantly predicting PTSD above the cut-off point with an overall diagnostic efficacy of $78.2 \%\left[\chi^{2}(2)=35.30\right.$, $P<0.001$, Nagelkerke $\left.R^{2}=0.486\right]$. Peak HR responses and acceleration $>1 \mathrm{bpm}$ were entered in Step 2, but did not increase the prediction efficacy of the model $\left[\chi^{2}(4)=3.95\right.$,

Table 2. Hierarchical multiple regression results for psychological and physiological predictors of PTSD symptoms in the parental cancer group

\begin{tabular}{|c|c|c|c|}
\hline \multirow[b]{3}{*}{ Variables } & \multicolumn{3}{|c|}{ PTSD symptoms $\ddagger$} \\
\hline & \multirow[b]{2}{*}{$B$ Model 1} & \multicolumn{2}{|l|}{ Model 2} \\
\hline & & $B$ & $95 \% \mathrm{CI}$ \\
\hline Distress * & $0.036^{\star \star \star}$ & $0.038^{\star \star \star}$ & $(0.023,0.053)$ \\
\hline Burdent & $0.062^{\star \star}$ & $0.063^{\star \star}$ & $(0.019,0.106)$ \\
\hline Peak HR to unpleasant pictures & & $0.487^{\star \star}$ & $(0.142,0.832)$ \\
\hline HR acel. $>1 \mathrm{bpm}$ to unpleasant pictures & & -1.026 & $(-2.230,0.178)$ \\
\hline$R^{2}$ & 0.419 & 0.480 & \\
\hline F & $27.021^{\star \star \star}$ & $10.922^{\star \star \star}$ & \\
\hline$\Delta R^{2}$ & & 0.061 & \\
\hline$\Delta F$ & & 2.088 & \\
\hline
\end{tabular}

Note. $n=78$.

${ }^{\star}$ Depression Anxiety Stress Scales.

tBurden Assessment Scale.

$\neq$ Impact of Event Scale-Revised.

${ }^{\star \star} P<0.01,{ }^{\star \star \star} P<0.001$.

PTSD, post-traumatic stress disorder; CI, confidence interval; HR, heart rate. 
Table 3. Hierarchical logistic regression results for psychological and physiological predictors of PTSD severity in the parental cancer group

\begin{tabular}{|c|c|c|c|c|c|c|}
\hline \multirow[b]{3}{*}{ Variables } & \multicolumn{6}{|l|}{ PTSD severity§ } \\
\hline & \multicolumn{3}{|l|}{ Model 1} & \multicolumn{3}{|l|}{ Model 2} \\
\hline & $B(\mathrm{SE})$ & OR & CI $95 \%$ & $B(\mathrm{SE})$ & OR & CI $95 \%$ \\
\hline Distress & $0.062^{\star \star}(0.019)$ & 1.064 & $(1.024,1.105)$ & $0.066^{\star \star}(0.020)$ & 1.068 & $(1.028,1.111)$ \\
\hline Burden $\neq$ & $0.088^{*}(0.038)$ & 1.092 & $(1.013,1.177)$ & $0.089 *(0.040)$ & 1.093 & $(1.010,1.183)$ \\
\hline Peak HR to unpleasant pictures & & & & $0.555(0.334)$ & 1.742 & $(0.905,3.353)$ \\
\hline HR acel. $>1 \mathrm{bpm}$ to unpleasant pictures & & & & $-1.226(1.050)$ & 0.293 & $(0.037,2.296)$ \\
\hline $\mathrm{R}^{2}$ Nagelkerke & 0.486 & & & 0.528 & & \\
\hline$-2 \log$ & 72.361 & & & 68.406 & & \\
\hline
\end{tabular}

Note. $n=78$

tDepression Anxiety Stress Scales.

¥Burden Assessment Scale.

$\S$ Considering cut-off point on the Impact of Event Scale-Revised.

${ }^{\star} P<0.05,{ }^{\star \star} P<0.01,{ }^{\star \star \star}{ }^{\star} P<0.001$.

CI, confidence interval; OR, odds ratio; HR, heart rate.

$P=0.412$, Nagelkerke $\left.R^{2}=0.528\right]$, since it decreased to $76.9 \%$ (Table 3).

\section{DISCUSSION}

This preliminary investigation studied the presence of enhanced psychological morbidity and physiological reactivity to emotional stimuli in adult children caregivers with parental cancer, compared with matched controls (without chronically ill parents). Additionally, this study investigated if the HR responses contributed to the prediction of PTSD symptoms, and probable diagnosis, in the parental cancer group, given the scarce controlled studies relating emotional distress and cardiovascular reactivity among cancer caregivers (Chentsova-Dutton et al. 2002; Lucini et al. 2008; Corà et al. 2012). As expected, adult children caregivers showed higher symptoms of distress, burden, and PTSD compared with controls. These differences were also significant for PTSD severity, since the cut-off determined a six times higher likelihood of a PTSD diagnosis (36 vs. 10 cases) in the parental cancer group. However, although the cut-off did not have sufficient sensitivity $(46 \%)$, it exceeded the minimum of $75 \%$ for specificity $(87 \%)$, being therefore useful for diagnostic purposes. The moderate sensitivity indicates that there may be several pathways to PTSD severity in parental cancer caregivers, being physiological vulnerability an important cue to be further explored. These results support previous findings on affective disorders in caregivers and suggest a similarity between psychological consequences of caregiving in dementia (Vitaliano et al. 2003) and in cancer settings (Corà et al. 2012).
With respect to the physiological variables, results showed that adult children caregivers seem to be in greater risk for stress-related disorders. In the present study, although HR had a moderately wide normal range between participants, several studies specify that it can be considered a significant precursor of cardiovascular risk (Palatini \& Julius 1997; Fox et al. 2007; Palatini 2009; Cooney et al. 2010). In general, HR levels were not clinically elevated, when compared with controls. Nevertheless, cancer caregivers tended to show higher HR parameters, with significant differences in some measurements (baseline and mean pre-stimulus baseline) for all picture types. Moreover, for unpleasant stimulus presentation, the differences were more noticeable. In the present study, adult children with parental cancer showed greater HR mean responses to unpleasant pictures than controls, as indicated by a higher HR, associated a lower mean deceleration and a trend for greater mean peak responses. The fact that the control group showed an HR deceleration to the unpleasant pictures can be interpreted as an orienting response, resembled to healthy volunteers' responses to unpleasant pictures reported in previous investigations (Lang et al. 1993; Bradley et al. 2001). There was a significant higher proportion of participants from the parental cancer group showing HR acceleration above $1 \mathrm{bpm}$, what could be interpreted as a heightened activation of the defensive system (Bradley et al. 1996). Supporting these results was the finding that for each second (except for the fourth one, on which only a trend was found) of unpleasant pictures presentation, the parental cancer group revealed a heightened HR response. This result can be interpreted as a learned fear response 
to stimuli (Brunetti et al. 2010; Suendermann et al. 2010). Indeed, higher HR responses have been associated with higher frequency of reported autonomic symptoms, thus suggesting a possible psychophysiological pathway to stress-related cardiovascular dysfunctions, as indicated by previous findings (Lucini et al. 2008). Actually, elevated HR during stressful situations has been previously observed in long-lasting caregiving for dementia patients (Vitaliano et al. 1993). In fact, elevated HR may also compromise life expectancy, not only in patients with hypertension or diabetes but also in subjects free of disease (Jouven et al. 2009). Together, these results indicate that the risk associated with the acceleration of HR is not only statistically significant but also clinically relevant, and should be considered when evaluating caregivers or even patients (Perret-Guillaume et al. 2009). These results can drive health professionals to pay attention to caregivers' cardiac activity, and to recommend lifestyle changes or pharmacological treatment, in order to reduce cardiovascular risk.

For electrodermal reactivity, significant group differences were also found. The parental cancer group showed a higher SC tonic activity at baseline, but also a heightened SC magnitude of the response to unpleasant, neutral, and pleasant pictures. The number of published studies using SC as a measure of autonomic activity to stressors in family care providers in oncology is, to our knowledge, non-existent. In fact, researchers who study the impact of parental cancer are beginning to draw attention to the gap of biophysical methods in this area (Su \& Ryan-Wenger 2007). However, it is important to note that some studies show SC increase in care-related activities. For example, maritally satisfied spouses show higher SC activation (considered a physiological 'forerunner' of empathy) compared with dissatisfied spouses, when listening to their partners describing the impact of pain on their daily lives (Stampler et al. 1997). In studies with caregivers of Alzheimer patients, although no significant differences were found in SC response by gender, men reported 'feeling' more relaxed than women (Thompson et al. 2004), whereas male Caucasian caregivers (compared with Mexican-Americans) showed lower electrodermal reactivity towards cognitive stimulation (Lewis et al. 2008). Although the present study did not intend to study gender or cultural/race differences, these results may motivate future research regarding physiological reactivity in men and women caregivers with different cultural backgrounds.

The last aim of the present study was to examine whether the magnitude of autonomic indices was directly related to PTSD symptoms and severity in participants with parental cancer. It would be expected that distress and burden would predict higher PTSD symptoms, not only because they were significantly correlated, but also given the extensive literature on this topic (Vanderwerker et al. 2005; Thomas et al. 2012). An increasing number of studies showed that heightened physiological reactivity to trauma-related cues is indicative of a PTSD diagnosis (Orr \& Roth 2000; Kibler \& Lyons 2004; Ehlers et al. 2010). In particular, heightened HR response to standardised sets of trauma cues appeared to be an effective indicator of vulnerability to PTSD (Lindauer et al. 2006), reflecting an elevated sensitivity to unconditioned aversive stimuli (Orr \& Roth 2000; O’Donnell et al. 2007). Previous reports showed that peak HR responses were an effective indicator of PTSD (Blanchard et al. 1996; Elsesser et al. 2005), as the cardiac acceleration above $1 \mathrm{bpm}$ (Ehlers et al. 2010). In the present study, the HR peak response to unpleasant pictures increased significantly the predictive accuracy for higher PTSD symptoms, controlling for distress and burden. Even though HR peak responses to neutral and pleasant pictures, and the acceleration $>1 \mathrm{bpm}$ to unpleasant pictures, did not contribute to the explained variance, the hypothesis was confirmed. Contrary to Ehlers et al. (2010), the logistic regression with HR response to unpleasant pictures (peak response or acceleration $>1 \mathrm{bpm}$ ) did not differentiate parental cancer participants with and without probable PTSD. However, the results are clinically relevant, suggesting that psychophysiological responses (specially HR responses) may be useful in identifying and treating cancer caregivers at risk for PTSD.

Some limitations and strengths of the present study must be acknowledged. This is the first known research study with a psychophysiological design comprising a sample of adult children caregivers in a parental cancer condition, compared with a matched control group. Important implications can be derived from present data, since it seems quite evident that parental cancer prompts psychological consequences that are 'visible' through assessment tools of peripheral autonomic responses. Another strength of the present study is the large sample size. There is not ample evidence that validates the effects of cancer patients' caregiving over time (Nijboer et al. 1998). Even though participants have been selected without any evidence of cardiovascular disease and properly matched, the cross-sectional design limits causal relationships between physiological correlates and PTSD symptoms. However, the obtained results are in accordance with previous longitudinal designs, reporting an elevated HR responsiveness in trauma victims that developed PTSD (Shalev et al. 1998; Bryant et al. 2003). For 
example, prolonged assessments extending from the early phases of caregiving, for different stages of oncological disease, and in different contexts (e.g. home care, outpatient, chemotherapy, palliative care), should be taken in consideration, as well, in future research. It is always a sensitive issue the selected way to minimise the presence of a measurement bias in physiological research designs, due to its large variability. Thus, an additional limitation is the non-inclusion of the respiratory sinus arrhythmia (RSA) record, a well-known marker of vagal HR control (Watkins et al. 1998). Finally, although the selected IAPS pictures were classified by volunteers in the pilot study, a further limitation is the non-inclusion of an additional assessment task of pictures in the parental cancer group (e.g. using the Self-Assessment Manikin; Lang 1980). It would be interesting to verify if there was a correspondence between these self-assessments (in terms of arousal and valence) and physiological correlates. In fact, the IAPS is a pictorial tool with limitations when applied to people in distress, mainly because it was designed to evaluate emotions in laboratory, i.e. it remains doubtful whether, in a real life context, the results would remain the same. Moreover, it is not quite clear whether the emotional and physiological reactions revealed, by adult children caregivers, are related to the caregiving situation or if responses are generalised to any individual in the presence of the same aversive stimuli.
In conclusion, the results of the present study confirm that caregiving for a parent with cancer is a stressful condition with potentially negative physiological and psychological consequences (Pedersen \& Revenson 2005), highlighting the importance of screening caregivers for both outcome reactions. The inclusion of cardiovascular variables in routine assessment can provide a more comprehensive picture of the psychophysiological risk associated with parental caregiving, thus decreasing its negative impact on physical and psychological health. With these results, a contribution is made to the advancement of knowledge of the physiological mechanisms involved in psychological morbidity in caregivers of cancer patients, with the ultimate aim of improving the diagnosis and prognosis of symptoms associated with this population. Finally, present findings allow an improvement in intervention and treatment of these individuals. These results suggest the need to carry out preventive strategies in this population, in order to improve the autonomic profile of caregivers in oncology.

\section{ACKNOWLEDGEMENTS}

This study was funded by a grant from the Portuguese Foundation for Science and Technology, granted to the first author (reference SFRH/BD/43275/2008). The authors have no conflicts of interest to disclose.

\section{REFERENCES}

American Psychiatric Association (2000) Diagnostic and Statistical Manual of Mental Disorders, 4th edn. text rev. Author, Washington, DC, USA.

Arangüena L. \& Dorado J. (2000) Psicofisiologia. Fundamentos Metodológicos [Psychophysiology. Methodological Foundations]. Pirámide, Madrid, Spain.

Baider L., Ever-Hadani P. \& Kaplan De-Nour A. (1999) Psychological distress in healthy women with familial breast cancer: like mother, like daughter? International Journal of Psychiatry in Medicine 29, 411-420.

Blanchard E.B., Hickling E.J., Buckley T.C., Taylor A.E., Vollmer A. \& Loos W.R. (1996) Psychophysiology of posttraumatic stress disorder related to motor vehicle accidents: replication and extension. Journal of Consulting and Clinical Psychology 64, 742-751.

Bradley M.M., Cuthbert B.N. \& Lang P.J. (1996) Picture media and emotion: effects of a sustained affective context. Psychophysiology 33, 662-670.
Bradley M.M., Codispoti M., Cuthbert B.N. \& Lang P.J. (2001) Emotion and motivation I: defensive and appetitive reactions in picture processing. Emotion 1, 276298.

Brunetti M., Sepede G., Mingoia G., Catani C., Ferretti A., Merla A., Del Gratta C., Romani G.L. \& Babiloni C. (2010) Elevated response of human amygdala to neutral stimuli in mild post traumatic stress disorder: neural correlates of generalized emotional response. Neuroscience 168, 670-679.

Bryant R.A., Harvey A.G., Guthrie R.M. \& Moulds M.L. (2003) Acute psychophysiological arousal and posttraumatic stress disorder: a two-year prospective study. Journal of Traumatic Stress 16, 439-443.

Chentsova-Dutton Y., Shuchter S., Hutchin S., Strause L., Burns K. \& Zisook S. (2000) The psychological and physical health of hospice caregivers. Annals of Clinical Psychiatry 12, 19-27.

Chentsova-Dutton Y., Shucter S., Hutchin S., Strause L., Burns K., Dunn L., Miller M. \& Zisook S. (2002) Depression and grief reaction in hospice caregivers: from pre-death to 1 year afterwards. Journal of Affective Disorders 69, 53-60.

Cooney M.T., Vartiainen E., Laakitainen T., Juolevi A., Dudina A. \& Graham I.M. (2010) Elevated resting heart rate is an independent risk factor for cardiovascular disease in healthy men and women. American Heart Journal 159, 612-619.

Corà A., Partinico M., Munafò M. \& Palomba D. (2012) Health risk factors in caregivers of terminal cancer patients: a pilot study. Cancer Nursing 35, 38-47.

Creamer M., Bell R. \& Failla S. (2003) Psychometric properties of the Impact of Event Scale - Revised. Behaviour Research and Therapy 41, 1489-1496.

Dawson M.E., Schell A.M. \& Filion D.L. (2007) The electrodermal system. In: Handbook of Psychophysiology, 3rd edn (eds Cacioppo J.T., Tassinary L.G. \& Berntson G.G.), pp. 159-181. Cambridge University Press, New York, NY, USA.

Dimsdale J.E. (2008) Psychological stress and cardiovascular disease. Journal of the American College of Cardiology 51, 1237-1246.

Ehlers A., Suendermann O., Boellinghaus I., Vossbeck-Elsebusch A., Gamer M., 
Briddon E., Martin M.W. \& Glucksman E. (2010) Heart rate responses to standardized trauma-related pictures in acute posttraumatic stress disorder. International Journal of Psychophysiology 78, 27-34.

Elsesser K., Sartory G. \& Tackenberg A. (2004) Attention, heart rate, and startle response during exposure to traumarelevant pictures: a comparison of recent trauma victims and patients with posttraumatic stress disorder. Journal of Abnormal Psychology 113, 289-301.

Elsesser K., Sartory G. \& Tackenberg A. (2005) Initial symptoms and reactions to trauma-related stimuli and the development of posttraumatic stress disorder. Depression and Anxiety 21, 61-70.

Elsesser K., Freyth C., Lohrmann T. \& Sartory G. (2009) Dysfunctional cognitive appraisal and psychophysiological reactivity in acute stress disorder. Journal of Anxiety Disorders 23, 979985.

Erblich J., Bovbjerg D.H. \& Valdimarsdottir H.B. (2000) Looking forward and back: distress among women at familial risk for breast cancer. Annals of Behavioral Medicine 22, 53-59.

Field A. (2006) Discovering Statistics Using SPSS: And Sex and Drugs and Rock 'N' Roll. Sage Publications, London, UK.

Fox K., Borer J.S., Camm A.J., Danchin N., Ferrari R., Lopez Sendon J.L., Steg P.G., Tardif J.C., Tavazzi L. \& Tendera M. (2007) Resting heart rate in cardiovascular disease. Journal of the American College of Cardiology 50, 823-830.

Gallagher-Thompson D., Shurgot G.R., Rider K., Gray H.L., McKibbin C.L., Kraemer H.C., Sephton S.E. \& Thompson L.W. (2006) Ethnicity, stress, and cortisol function in Hispanic and non-Hispanic white women: a preliminary study of family dementia caregivers and noncaregivers. American Journal of Geriatric Psychiatry 14, 334-342.

Hamm A.O., Cuthbert B.N., Globisch J. \& Vaitl D. (1997) Fear and the startle reflex: blink modulation and autonomic response patterns in animal and mutilation fearful subjects. Psychophysiology 34, 97-107.

Hauser J.M. \& Kramer B.J. (2004) Family caregivers in palliative care. Clinics in Geriatric Medicine 20, 671-688.

Jennings J.R. \& Gianaros P.J. (2007) Methodology. In: Handbook of Psychophysiology, 3rd edn (eds Cacioppo J.T., Tassinary L.G. \& Berntson G.G.), pp. 812-833. Cambridge University Press, New York, NY, USA.

Jouven X., Empana J.P., Escolano S., Buyck J.F., Tafflet M., Desnos M. \& Ducimetière P. (2009) Relation of heart rate at rest and long-term ( $>20$ years) death rate in initially healthy middleaged men. American Journal of Cardiology 103, 279-283.

Kibler J.L. \& Lyons J.A. (2004) Perceived coping ability mediates the relationship between PTSD severity and heart rate recovery in veterans. Journal of Traumatic Stress 17, 23-29.

Kiecolt-Glaser J.K., Preacher K.J., Maccallum R.C., Atkinson C., Malarkey W.B. \& Glaser R. (2003) Chronic stress and age-related increases in the proinflammatory cytokine IL-6. Proceedings of the National Academy of Sciences of the United States of America 100, 90909095.

Korneluk Y.G. \& Lee C.M. (1998) Children's adjustment to parental physical illness. Clinical Child and Family Psychology Review 1, 179-193.

Lang P.J. (1980) Behavioral treatment and bio-behavioral assessment: computer applications. In: Technology in Mental Health Care Delivery Systems leds Sidowski J.B., Johnson J.H. \& Williams T.A.), pp. 119-137. Ablex, Norwood, NI, USA.

Lang P.J., Greenwald M.K., Bradley M.M. \& Hamm A.O. (1993) Looking at pictures: affective, facial, visceral, and behavioral reactions. Psychophysiology 30, 261273.

Lang P.J., Bradley M.M. \& Cuthbert B.N. (2008) International Affective Picture System (IAPS): Affective Ratings of Pictures and Instruction Manual. Technical Report A-8. University of Florida, Gainsville, FL, USA.

Lerman C., Daly M., Sands C., Balshem A., Lustbader E., Heggan T., Goldstein L., James J. \& Engstrom P. (1993) Mammography adherence and psychological distress among women at risk for breast cancer. Journal of the National Cancer Institute 85, 1074-1080.

Levinson D.F. \& Edelberg R. (1985) Scoring criteria for response latency and habituation in electrodermal research: a critique. Psychophysiology 22, 417-426.

Lewis S.L., Escamilla M. \& Novian A. (2008) Comparison of emotional and biological parameters in Mexican American and white male and female caregivers of patients with Alzheimer's disease. Paper presented at the National State of the Science Congress on Nursing Research, Washington, DC, USA.

Lindauer R.T., Van Meijel E.P., Jalink M., Olff M., Carlier I.V. \& Gersons B.P. (2006) Heart rate responsivity to script-driven imagery in posttraumatic stress disorder: specificity of response and effects of psychotherapy. Psychosomatic Medicine 68, 33-40.

Lindberg N.M. \& Wellisch D.K. (2004) Identification of traumatic stress reactions in women at increased risk for breast cancer. Psychosomatics 45, 7-16.

Lovibond P.F. \& Lovibond S.H. (1995) The structure of negative emotional states: comparison of the Depression Anxiety Stress Scales (DASS) with the Beck Depression and Anxiety Inventories. Behaviour Research and Therapy 33, 335-343.

Lucini D., Cannone V., Malacarne M., Bruno D., Beltrami S., Pizzinelli P., Piazza E., Di Fede G. \& Pagani M. (2008) Evidence of autonomic dysregulation in otherwise healthy cancer caregivers: a possible link with health hazard. European Journal of Cancer 44, 2437-2443.

Moya-Albiol L., Sanchis-Calatayud M.V., Sariñana-González P., Andrés-García S., Romero-Martínez Á. \& González-Bono E. (2011) Electrodermal activity in response to a set of mental tasks in caregivers of persons with autism spectrum disorders. European Psychiatry (Abstracts of the 19th European Congress of Psychiatry) 26, 1595

Nijboer C., Tempelaar R., Sanderman R., Triemstra M., Spruijt R.J. \& Van Den Bos G.A. (1998) Cancer and caregiving: the impact on the caregiver's health. PsychoOncology 7, 3-13.

O’Donnell M.L., Creamer M., Elliott P. \& Bryant R. (2007) Tonic and phasic heart rate as predictors of posttraumatic stress disorder. Psychosomatic Medicine 69, 256-261.

Orr S.P. \& Kaloupek D.G. (1997) Psychophysiological assessment of posttraumatic stress disorder. In: Assessing Psychological Trauma and PTSD (eds Wilson I.P. \& Keane T.M.), pp. 69-97. The Guilford Press, New York, NY, USA. Orr S.P. \& Roth W.T. (2000) Psychophysiological assessment: clinical applications for PTSD. Journal of Affective Disorders 61, 225-240.

Pais-Ribeiro J.L., Honrado A. \& Leal I. (2004) Contribuição para o estudo da adaptação portuguesa das escalas de ansiedade, depressão e stress (EADS) de 21 itens de Lovibond e Lovibond [Contribution to the study of Portuguese adaptation of the 21 items depression, anxiety and stress scales (DASS) of Lovibond and Lovibond]. Psicologia, Saúde and Doenças 5, 229-239.

Palatini P. (2009) Elevated heart rate: a 'new' cardiovascular risk factor? Progress in Cardiovascular Diseases 52, 1-5.

Palatini P. \& Julius S. (1997) Heart rate and the cardiovascular risk. Journal of Hypertension 15, 3-17.

Pedersen S. \& Revenson T.A. (2005) Parental illness, family functioning, and adolescent well-being: a family ecology framework to guide research. Journal of Family Psychology 19, 404-409. 
Perret-Guillaume C., Joly L. \& Benetos A. (2009) Heart rate as a risk factor for cardiovascular disease. Progress in Cardiovascular Diseases 52, 6-10.

Pole N. (2007) The psychophysiology of posttraumatic stress disorder: a metaanalysis. Psychological Bulletin 133, 725-746.

Reinhard S.C., Gubman G.D., Horwitz A.V. \& Minsky S. (1994) Burden Assessment Scale for families of the seriously mentally ill. Evaluation and Program Planning 17, 261-269.

Rohleder N., Marin T.J., Ma R. \& Miller G.E. (2009) Biologic cost of caring for a cancer patient: dysregulation of pro- and anti-inflammatory signaling pathways. Journal of Clinical Oncology 27, 29092915.

Schulz R. \& Beach S.R. (1999) Caregiving as a risk factor for mortality: the Caregiver Health Effects Study. Journal of the American Medical Association 282, 2215-2219.

Schulz R., O’brien A.T., Bookwala J. \& Fleissner K. (1995) Psychiatric and physical morbidity effects of dementia caregiving: prevalence, correlates, and causes. The Gerontologist 35, 771-791.

Sequeira H., Hot P., Silvert L. \& Delplanque S. (2009) Electrical autonomic correlates of emotion. International Journal of Psychophysiology 71, 50-56.

Shalev A.Y., Sahar T., Freedman S., Peri T., Glick N., Brandes D., Orr S.P. \& Pitman R.K. (1998) A prospective study of heart rate responses following trauma and the subsequent development of posttraumatic stress disorder. Archives of General Psychiatry 55, 553-559.

Shaw W.S., Patterson T.L., Semple S.J., Dimsdale J.E., Ziegler M.G. \& Grant I. (2003) Emotional Expressiveness, hostility and blood pressure in a longitudinal cohort of Alzheimer caregivers. Journal of Psychosomatic Research 54, 293302.

Sherwood P.R., Given B.A., Donovan H., Baum A., Given C.W., Bender C.M. \& Schulz R. (2008) Guiding research in family care: a new approach to oncology caregiving. Psycho-Oncology 17, 986996.
Stampler D.B., Wall J.R., Cassisi J.E. \& Davis H. (1997) Marital satisfaction and psychophysiological responsiveness in spouses of patients with chronic pain. International Journal of Rehabilitation and Health 3, 159-170.

Su Y.H. \& Ryan-Wenger N.A. (2007) Children's adjustment to parental cancer: a theoretical model development. Cancer Nursing 30, 362-381.

Suendermann O., Ehlers A., Boellinghaus I., Gamer M. \& Glucksman E. (2010) Early heart rate responses to standardized trauma-related pictures predict posttraumatic stress disorder: a prospective study. Psychosomatic Medicine 72, 301-308.

Tabachnick B.G. \& Fidell L.S. (2006) Using Multivariate Statistics. Harper Collins Publishers, New York, NY, USA.

Thomas K.S., Bower J.E., Williamson T.J., Hoyt M.A., Wellisch D., Stanton A.L. \& Irwin M. (2012) Post-traumatic disorder symptoms and blunted diurnal cortisol production in partners of prostate cancer patients. Psychoneuroendocrinology 37, 1181-1190.

Thompson R.L., Lewis S.H., Murphy M.R., Hale J.M., Blackwell P.H., Acton G.J., Clough D.H., Patrick G.J. \& Bonner P.N. (2004) Are there sex differences in emotional and biological responses in spousal caregivers of patients with Alzheimer's disease? Biological Research for Nursing 5, 319-330.

Vanderwerker L.C., Laff R.E., KadanLottick N.S., McColl S. \& Prigerson H.G. (2005) Psychiatric disorders and mental health service use among caregivers of advanced cancer patients. Journal of Clinical Oncology 23, 68996907.

Vedhara K., Cox N.K., Wilcock G.K., Perks P., Hunt M., Anderson S., Lightman S.L. \& Shanks N.M. (1999) Chronic stress in elderly carers of dementia patients and antibody response to influenza vaccination. Lancet 353, 627-631.

Venables P.H. \& Christie M.J. (1980) Electrodermal activity. In: Techniques in Psychophysiology (eds Martin I. \& Venables P.H.), pp. 3-67. John Wiley \& Sons, Chichester, UK
Vitaliano P.P., Russo J., Bailey S.L., Young H.M. \& McCann B.S. (1993) Psychosocial factors associated with cardiovascular reactivity in older adults. Psychosomatic Medicine 55, 164-177.

Vitaliano P.P., Scanlan J.M., Zhang J., Savage M.V., Hirsch I.B. \& Siegler I.C. (2002) A path model of chronic stress, the metabolic syndrome, and coronary heart disease. Psychosomatic Medicine 64, 418-435.

Vitaliano P.P., Zhang J. \& Scanlan J.M. (2003) Is caregiving hazardous to one's physical health? a meta-analysis. Psychological Bulletin 129, 946-972.

Von Känel R., Dimsdale J.E., Mills P.J., Ancoli-Israel S., Patterson T.L., Mausbach B.T. \& Grant I. (2006) Effect of Alzheimer caregiving stress and age on frailty markers interleukin-6, C-reactive protein, and D-dimer. The Journals of Gerontology 6, 963-969.

Wang L., Zhang J., Shi Z., Zhou M., Huang D. \& Liu P. (2011) Confirmatory factor analysis of posttraumatic stress symptoms assessed by the Impact of Event Scale-Revised in Chinese earthquake victims: examining factor structure and its stability across sex. Journal of Anxiety Disorders 25, 369-375.

Watkins L.L., Grossman P., Krishnan R. \& Sherwood A. (1998) Anxiety and vagal control of heart rate. Psychosomatic Medicine 60, 498-502.

Weiss D. \& Marmar C. (1997) The impact of event scale-revised. In: Assessing Psychological Trauma and PTSD: A Practitioner's Handbook (eds Wilson J.P. \& Keane T.M.), pp. 399-411. Guilford Press, New York, NY, USA.

Weitzner M., Haley W. \& Chen H. (2000) The family caregiver of the older cancer patient. Hematology/Oncology Clinics of North America 14, 269-281.

Zakowski S.G., Valdimarsdottir H.B., Bovbjerg D.H., Borgen P., Holland J., Kash K., Miller D., Mitnick J., Osborne M. \& Van Zee K. (1997) Predictors of intrusive thoughts and avoidance in women with family histories of breast cancer. Annals o Behavioral Medicine 19, 362-369. 